\title{
Feasibility study of highway project in the environment sensitive area of Western China -- Based on the magic cube model of construction necessity and ecological friendliness
}

\author{
Gaoru Zhu ${ }^{1}$, Kun $\mathrm{Hu}^{2}$, Long $\mathrm{Li}^{3}$, Yujian $\mathrm{Gao}^{1}$, Jing Lin ${ }^{1}$, Honglei $\mathrm{Xu}^{1 *}$, Dong $\mathrm{Han}^{2}$, Dafang $\mathrm{Wu}^{3}$, Jie Liu ${ }^{1 *}$ \\ ${ }^{1}$ Planning and research institute of the ministry of transport, Beijing 100028, China; ${ }^{2}$ Qinghai Highway Construction Administration \\ Bureau, Xining 810008; ${ }^{3}$ School of geographical sciences, Guangzhou University, Guangzhou 510006, China
}

\begin{abstract}
Under the background of the strategy of "strong transportation country", the feasibility study of highway network construction is a hot topic in academic fields such as highway line selection. It is also an important means to promote development of eco-sensitive regions such as Sanjiangyuan in Qinghai-Tibet plateau. We selected 17 indexes of construction necessity and 9 indexes of ecological friendliness to evaluate the feasibility of highway network construction. The indexes were weighted by the analytic hierarchy process (AHP) and expert scoring method. Furthermore, we used comprehensive factor evaluation model to quantify the construction necessity and ecological friendliness of planning highways in Sanjiangyuan. Finally, we used the magic cube model to calculate the score of construction feasibility. The result shows the number of planning highways with high, relatively-high, medium, relatively-low and low construction feasibility is $16,11,11,11$ and 1 , respectively. The feasibility of planning highway construction in the eastern and western region of Sanjiangyuan is similar generally, which don't have big interregional difference. Results of this study can provide technical support and theoretical basis for regional highway network construction and traffic route planning in underdeveloped areas in the West China.
\end{abstract}

\section{Introduction}

The construction of ecological civilization, as an important part of the overall layout of "five-in-one" and the strategic layout of "four comprehensives", is the fundamental principle of high-quality development in China's new era ${ }^{[1]}$. We should guide the overall economic and social development with the concept of ecological protection as the priority, explore the road of green and scientific development in underdeveloped areas. And we make every effort to promote the "four transformations" to become a transportation power ${ }^{[2]}$. As a pioneer of development, transportation construction has been carrying out extensive exploration in the field of highway ecological protection by insisting on "ecological priority and green development", promoting "green transportation" and building "green roads" [3].

The coordinated development of ecological environment and highway construction is an important part of sustainable development strategy and assessment of environmental impact. Domestic and foreign transportation departments and relevant scholars made a lot of exploration in this field and had rich research results. In view of the whole process of road planning, design, construction, maintenance and operation, the United States ${ }^{[4]}$, Sweden ${ }^{[5]}$, Australia ${ }^{[5]}$ and other countries have put forward requirements and measures for ecological environmental protection. Domestic and foreign scholars mainly study the impact of different grades of roads on the ecological environment ${ }^{[8]}$, and carry out coordinated assessment with the landscape along the highway ${ }^{[9]}$. Moreover, the index system of assessment of feasibility of highway construction is constantly enriched, which not only considers the necessity of construction, but also gradually increases the consideration of ecological factors ${ }^{[10-11]}$. Studies on environmental impact assessment of highway construction have been well applied in practice, such as anti-slip design of embankment slope ${ }^{[12]}$ and study on ecological restoration measures of slope ${ }^{[13]}$. In the existing studies, most scholars are to assess feasibility of highway construction from different dimensions and select the appropriate traffic line. They adopts the GIS, AHP and expert scoring method ${ }^{[14-15]}$ to quantitatively analyze of the relationship between highway construction and ecological protection, and adopt corresponding coordination measures. A great deal of studies and work has promoted the integrated development of highway traffic and ecological environment, which made big progress in theory, method, technology, etc.

Located in the hinterland of the Qinghai-Tibet plateau, Sanjiangyuan is the birthplace of the Yangtze river, the Yellow River and the Lancang river, as well as the sensitive and important starting area of climate change in Asia, the northern hemisphere and even the world. Its special geographical location, abundant natural resources

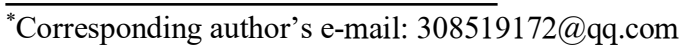


and important ecological functions make it an important ecological security barrier in China. Besides, the basic connectivity of the road network in Sanjiangyuan is relatively poor, which is inconvenient to travel, product and live. As an important link between Tibet and the mid-east regions, Tibet is also a contiguous region with severe poverty. It needs to build roads urgently owing to superior ecological resources and harsh environmental conditions, which is beneficial for socio-economic development, national strategy and poverty alleviation. Road construction is restricted by tougher ecological and environmental conditions in this region, so it is necessary to give priority to ecological factors and provide adequate support for people's livelihood.

At present, the feasibility study of highway construction from two perspectives including necessity and ecological friendliness is rarely reported. Therefore, this paper attempts to quantitatively study the necessity and ecological friendliness of highway construction from aspect of highway planning, and divides different construction feasibility levels by combining with the policy and technical analysis of highway ecological protection. It provides technical support and theoretical basis for the formulation of regional optimal highway network construction program and traffic route planning.

\section{Materials and methods}

\subsection{Study area}

Sanjiangyuan $\left(89^{\circ} 45^{\prime} \sim 102^{\circ} 23^{\prime} \mathrm{E}, 31^{\circ} 39^{\prime}-36^{\circ} 12^{\prime} \mathrm{N}\right)$ is the hinterland of the Tibetan plateau which covers an area of $36.3 \mathrm{~km}^{2}$. The topography of this region is mainly mountainous plateau, and it is very complex. It belongs to typical continental climate on the plateau with alternating hot and cold seasons and distinct dry and wet seasons. The difference of temperature is small in a year, large in a day. As area of origin of the Yangtze river, Yellow River and Lancang river, it owns abundant water, good ecological background conditions but fragile ecology. By the end of 2017, the total population of Sanjiangyuan was $1,361,700$, showing a continuous growth. And the demand for transportation infrastructure continued to strengthen. Agriculture and animal husbandry are the primary industries in the economic development of the Sanjiangyuan. At the end of 2017, highway mileage is to reach $41501 \mathrm{~km}$ and road network density is about $0.102 \mathrm{~km} / \mathrm{km}^{2}$. The scale is difficult to meet the transportation power, all the way, the Yangtze river economic belt of strategic needs and basic needs of the local people. Due to its inadequate scale and level, it is urgent to enhance the regional highway infrastructure.

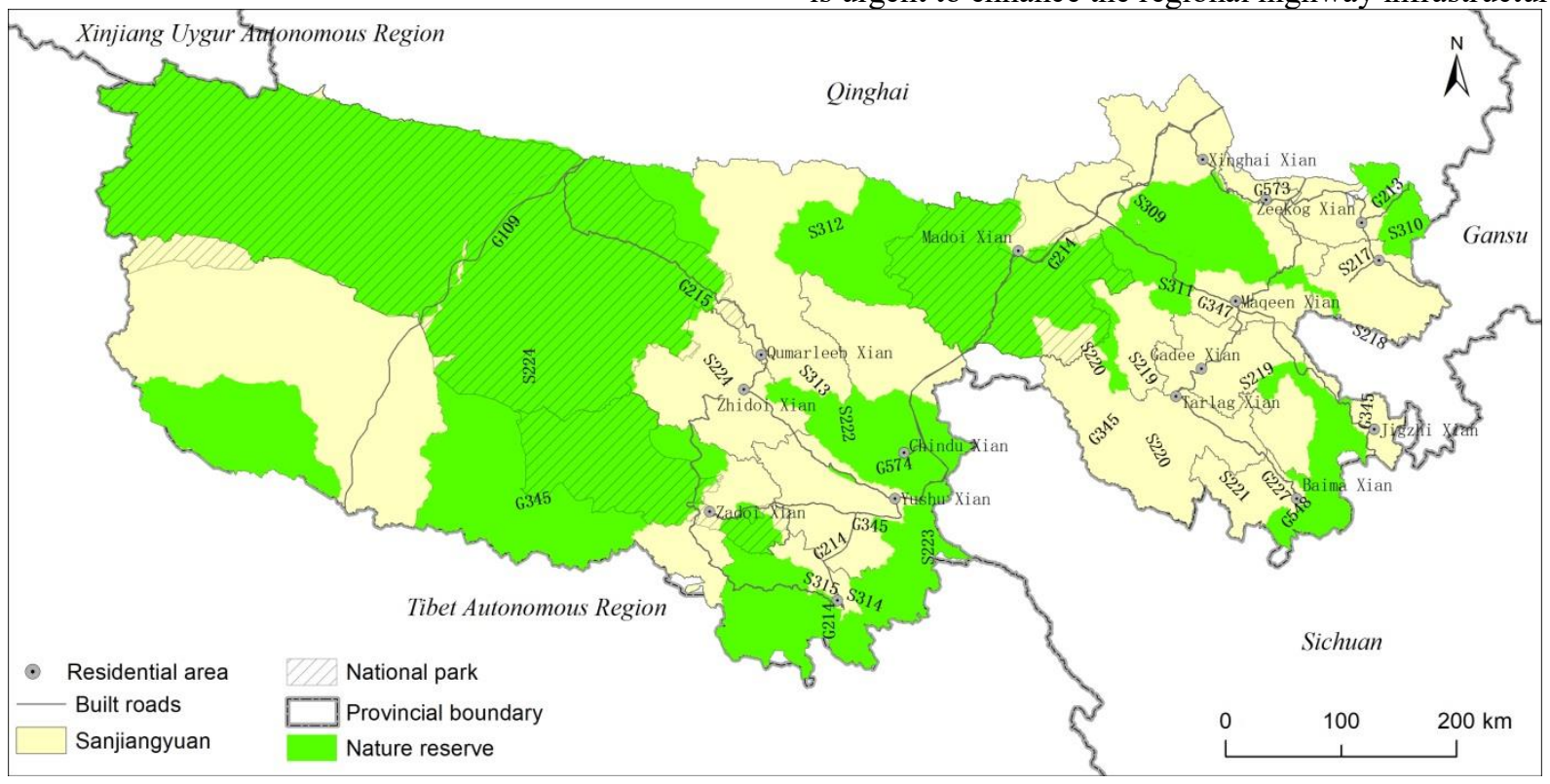

Figure 1 Study area

\subsection{Data sources}

Spatial data: the ecological data of nature reserves, national parks, and ecological red lines are derived from the databases of the general plan of national park in Sanjiangyuan, the infrastructure plan of Sanjiangyuan in Qinghai's national ecological protection comprehensive pilot zone, and the plan of Sanjiangyuan in Qinghai's ecological protection and construction phase ii project. The vector data of 50 planning highway (i.e., including newly-built and rebuilt projects) networks were obtained from the database of planning highway projects of Qinghai provincial department of transportation. The data of basic information such as administrative unit boundaries were obtained from the 1:400, 000 database of the national basic geographic information center.

Socio-economic data: national highway network planning (2013-2030), Qinghai's expressway network planning (2017-2035), Qinghai's provincial road network planning (2012-2030), Qinghai's rural road network development planning (2009-2030), Qinghai's transportation "13th five-year plan" development plan, 2019 statistical yearbook of Qinghai province, etc. 


\subsection{Establishment of indicator system}

2.3.1. Construction necessity. The main highway network of Qinghai province consists of the national highway and provincial highway, which mainly connects the major cities and towns in the province with the passenger and freight distribution points. Besides, it mainly undertakes the external traffic and transportation of the passenger and freight between the cities and the major towns. Moreover, it undertakes needs of maintaining national unity, supporting poverty alleviation, ensuring national defense security and responding to the implementation of national strategy. Therefore, we comb through systematically party central committee and the state council and ministries and the relevant laws and regulations of Qinghai province, strategy, policy and other documents requirements from perspectives of national unity, poverty alleviation and the national defense military and strategic emergency system. We combine the actual needs of production and living to select 17 key indicators for index system of construction necessity assessment.

Table 1 Assessment index of necessity of Sanjiangyuan highway construction

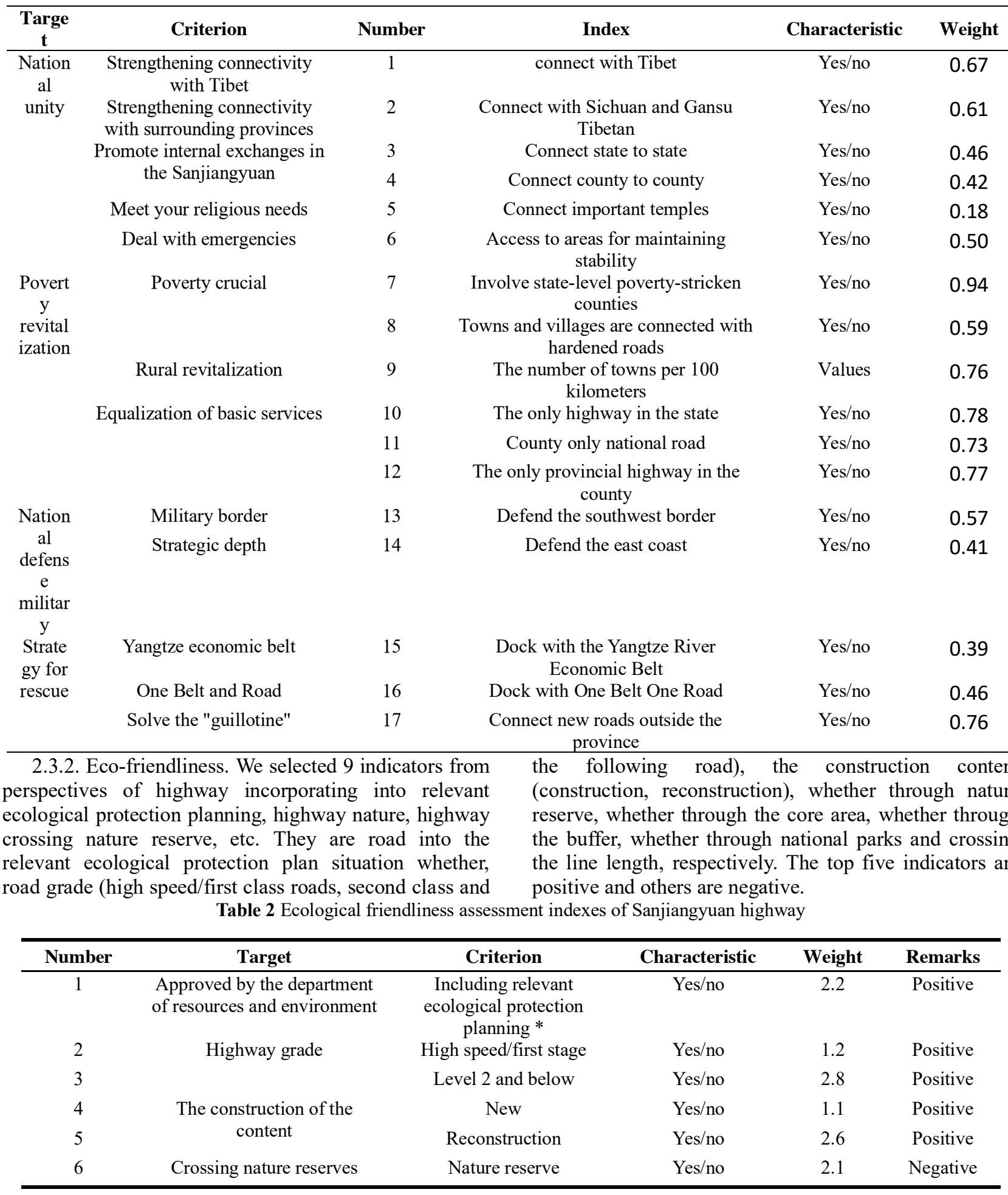




\begin{tabular}{cccccc}
\hline Number & Target & Criterion & Characteristic & Weight & Remarks \\
\hline 7 & & Through the core & Length & 3.2 & Negative \\
8 & & Buffer crossing & Length & 2.8 & Negative \\
9 & Across national parks & The national park & Yes/no & 1.9 & Negative \\
\hline
\end{tabular}

\subsection{Quantification of index}

In the assignment, the index with "yes/no" is assigned 1 and 0 respectively ; 3 successional indexes including the number of driven towns per 100 kilometers, the length of crossing the core area, and the length of crossing the buffer zone are quantified as $0 \sim 1$ based on normalized model.

\subsection{Definition of index weight}

Based on expert scoring method, we invite the nature reserve of China environmental science research institute, the state forestry administration research center, the ecological environment of Nanjing environmental science research institute, Chinese Academy of Sciences ecological environmental research center, Chinese academy of geological sciences research institute, the Ministry of Transport and transport highway research institute and other units responsible for red line nature reserve, ecological protection and related research of highway environmental protection of the ten leading experts to give the ten indexes weight.

\subsection{Assessment model}

2.6.1. Assessment of construction necessity. In this paper, we calculate the score of the necessity of each road construction based on the model of multi-factor comprehensive assessment. The calculation steps are as follows:

$$
N=\sum_{i=1}^{17} A_{i} \times B_{i}
$$

Where $N$ is the total score of the construction necessity of a highway, $A_{i}$ is the value assigned to $i$ th index, $B_{i}$ is the weight assigned to $i$ th index, and $i$ is the index (sum to 17). On this basis, all the 50 planning highways are ranked according to their scores, and they were divided into three grades by method of natural fracture. The construction necessity was "high" (score $>32)$, construction necessity is "medium" $(22<$ score $\leq 32$ ), construction necessity is "low" (score $\leq 22$ ).

2.6.2. Eco-friendliness assessment. Consistent with the method of assessment of construction necessity, the multi-factor comprehensive assessment method is adopted to calculate the score of ecological friendliness of each highway. The calculation steps are as follows:

$$
E=\sum_{i=1}^{5} A_{i} \times B_{i}-\sum_{i=6}^{9} A_{i} \times B_{i}
$$

Where $E$ is the total score of ecological friendliness of a highway, $A_{i}$ is the value assigned to $i$ th positive index, $B_{i}$ is the weight assigned to $i$ th negative index. Using the natural fracture method, results were divided into three grades: "high" for ecological friendliness (score $>2$ ), "medium" for ecological friendliness $(0<$ score $\leq 2$ ), "low" for ecological friendliness (score $\leq 0$ ).

2.6.3. Construction feasibility assessment. On the basis of the aforementioned studies on the construction necessity and ecological friendliness, we combine with the highway project level, the urgency of highway construction, and the situation of crossing the ecologically sensitive target to put forward feasible conclusions and suggestions on the construction environment for each highway by the magic cube model. Among them, the highway included in the "13th five-year plan" is high-urgency, and the highway included the national highway and national highway project is relatively important. The environmental feasibility is divided into five levels: high, relatively high, medium, relatively low and low. The corresponding relationship of the cube is shown in the table below.

\begin{tabular}{|c|c|c|c|}
\hline $\begin{array}{c}\text { Eco-friendliness } \\
\text { Construction } \\
\text { necessity }\end{array}$ & High & Middle & Low \\
\hline High & high & $\begin{array}{l}\text { relatively } \\
\text { high }\end{array}$ & $\begin{array}{c}\text { relatively } \\
\text { high }\end{array}$ \\
\hline Middle & $\begin{array}{l}\text { relatively } \\
\text { high }\end{array}$ & middle & $\begin{array}{c}\text { relatively } \\
\text { low }\end{array}$ \\
\hline Low & middle & $\begin{array}{c}\text { relatively } \\
\text { low }\end{array}$ & low \\
\hline
\end{tabular}

Table 3 Corresponding relationship of environmental feasibility

Note: urgency and importance of project are bonus points. If you meet them, the result will be improved one or two levels.

\section{Results}

\subsection{Construction necessity}

Among indexes of assessment, poverty alleviation, equalization of basic services and guillotine have higher weights. The construction necessity of all the planned 50 planning roads was assessed one by one (as shown in Fig.2), and the results showed that :(1) The number of planning roads with high, medium and low construction necessity was 15,20 and 25 , respectively. (2) The construction necessity of planned highways was generally higher in the western region than that in the eastern region. It was mainly because the western region was connected to Tibet and Tibetan areas in Gansu, and it had more poverty-stricken counties. (3) Among the highways with high construction necessity, the number of provincial highways was the largest, mainly because a large number of poor counties and highways were involved. (4) The necessity of national highway construction was generally higher than that of expressways and provincial highways, because the national highway was an inter-provincial connection line, which drive the largest number of towns and villages per 100 kilometers. At the same time, it connected with One Belt One Road and the Yangtze river economic belt, which was an important channel to achieve the national 
target. (5) The importance of S222, G309, S54 and other highways in the "low necessity" range was not high, so the schedule of construction could be delayed appropriately.

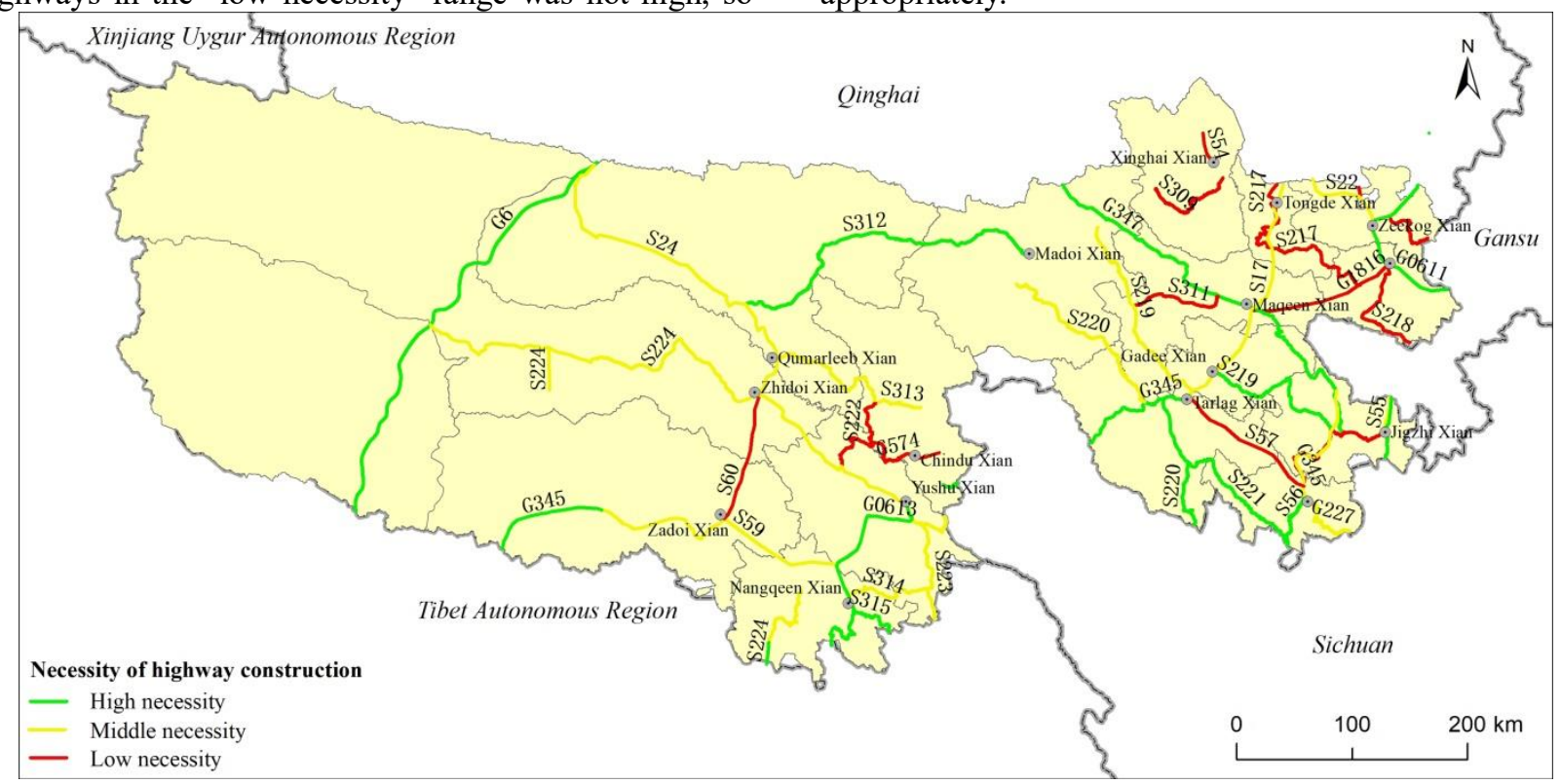

Figure 2 Assessment results of the necessity of highway network construction

\subsection{Ecological friendliness}

The ecological friendliness of 50 planning highway was assessed one by one (as shown in Fig.3), and the results showed that:(1) The number of planning roads with low, medium and high ecological friendliness was 15, 20 and 25, respectively. (2) The ecological friendliness of planned highways is generally lower in the western region than that in the eastern region, because ecologically sensitive resources were more in the western region. (3) Although the weight of newly built roads is lower than that of rebuilt and expanded roads, the difference was not obvious. Because many roads that need to be rebuilt and expanded were located in nature reserves or national parks. (4) The ecological friendliness of expressways was generally lower than that of ordinary national and provincial highways, because expressways were often long-span regional connecting lines, which have less avoidance of ecologically sensitive targets and greater impact on ecological environment. (5) S24, G345, S224 and other roads in the "low-friendliness" zone had stricter ecological constraints and needed to be focused in the preliminary work or process of specific projects.

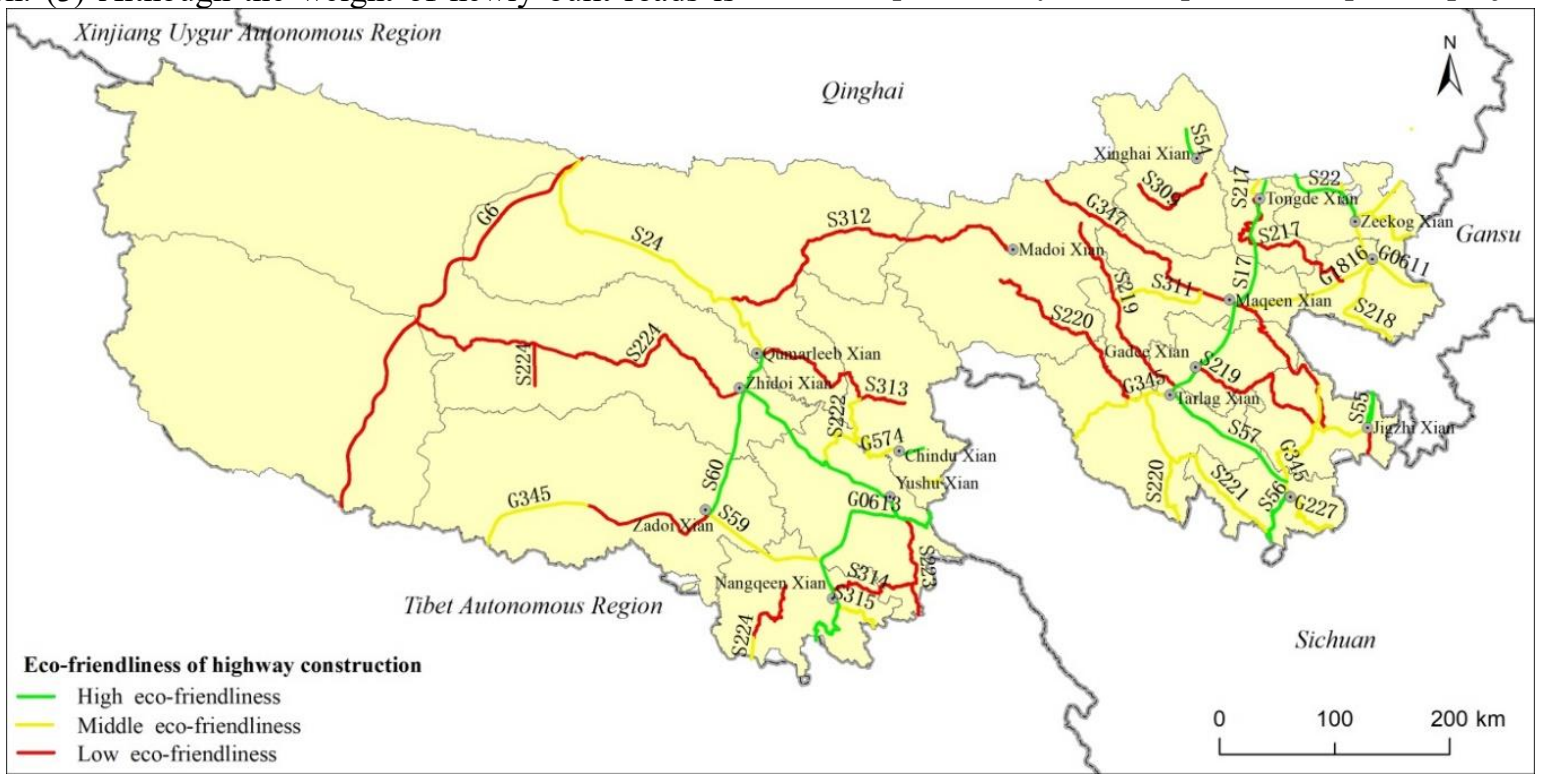

Figure 3 Assessment results of the Ecological friendliness of highway network construction

\subsection{Construction feasibility}

Based on results of construction necessity and ecological friendliness assessment, we combined with the level of highway construction, and the situation across the ecologically sensitive target to assess construction feasibility of all the planning of 50 planning highways 
(as shown in Fig.4), the results showed: (1) The number of planning highways with high, relatively high, medium, relatively low, low construction feasibility was $16,11,11$, 11 and 1, respectively. (2) Among the planning roads with high feasibility, the number of national highway was the largest, mainly due to the needs of ethnic unity, poverty alleviation and revitalization, national defense and military affairs, and less crossing ecologically sensitive areas. (3) The feasibility of highway construction in the western region is generally similar to that in the eastern region, mainly due to the mutual checks and balances between construction necessity and ecological friendliness, resulting in a low degree of spatial differentiation of highway construction feasibility.

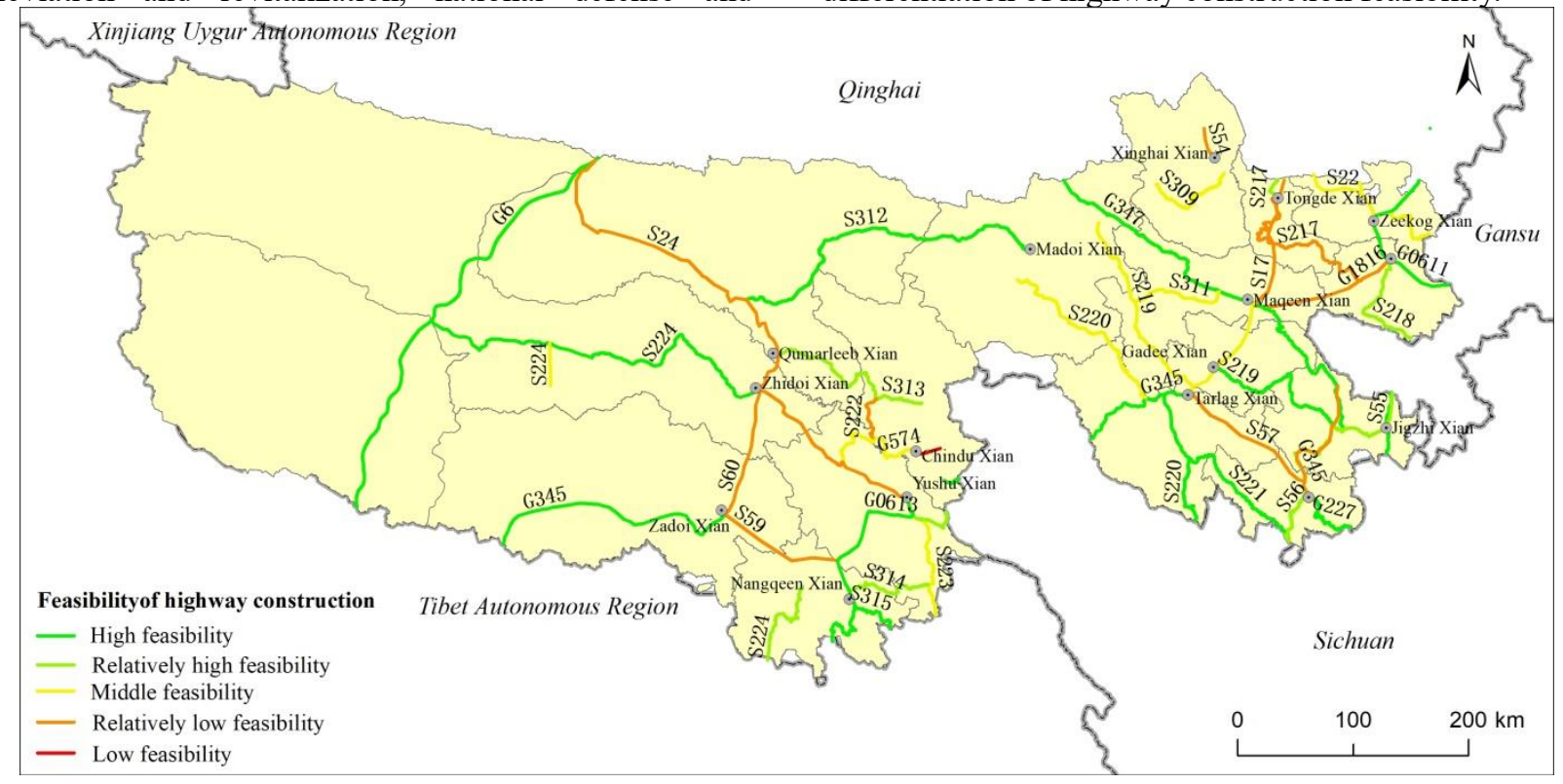

Figure 4 Assessment results of the feasibility of highway network construction

\section{Conclusions and discussion}

\subsection{Conclusions}

The coordinated development of ecological environment and highway construction is of great significance to the sustainable development of regional economy. In this study, 17 key indicators were firstly selected from the aspects of ethnic unity, poverty alleviation and revitalization, national defense and military affairs, strategic emergency response, and the actual needs of production and life to assess the necessity of planning highway construction. Secondly, 9 indicators were selected to evaluate the ecological friendliness of the planning highways from the perspectives of relevant ecological protection planning, highway nature and highway crossing nature reserve. Finally, based on the results of the two, we combined with the level and urgency of highway construction, the situation of crossing the ecologically sensitive target and used the magic cube model to assess the feasibility of each highway construction. There are the following conclusions:

(1) The construction necessity of planned highways in the western region is generally higher than that in the eastern region. The construction necessity of national highways is generally higher than that of expressways and provincial highways. We should strengthen the highway construction in Sanjiangyuan area under the premise of ecological protection, which is the key to strengthening the unity of nationalities, supporting poverty alleviation and rural revitalization, ensuring national defense and responding to the major national strategies and emergency needs.

(2) The ecological friendliness of planned highways in the western region is generally lower than that in the eastern region. The ecological friendliness of expressway is generally lower than that of ordinary national and provincial highways. G345 Jiuzhi to bamma section and other 25 new roads have good ecological friendliness. Generally speaking, the highway construction in Sanjiangyuan area has good ecological friendliness. Some of the roads are in the "low friendliness" zone, passing through more ecologically sensitive and nature reserves, which has strict ecological constraints.

(3) The number of planning highways with high, relatively high, medium, relatively low and low construction feasibility is $16,11,11,11$ and 1 , respectively. The feasibility of highway construction in the west is similar to that in the east, but the interregional difference is small. Construction feasibility of G0611 Tongren to Celong section and other 16 highways is high. For road sections with low feasibility, roads involving core areas or buffer zones of nature reserves can avoid ecologically sensitive areas by reasonable swing, and construction can be postponed or not if it is difficult to avoid.

(4) Through the preliminary exploration of quantitative evaluation methods for the necessity, ecological friendliness and feasibility of highway construction, the study provides theoretical support and technical support for the feasibility study of highway construction in western ecologically sensitive areas such as the Sanjiangyuan area. The feasibility of highway 
construction is assessed from two perspectives including the necessity such as ethnic unity, poverty alleviation and revitalization, and the ecological friendliness. Besides, the index system of assessment in this field is enriched, which is of great practical significance to the coordinated development of regional economy and ecology.

\subsection{Discussion}

The purpose of this study is to provide a method of feasibility assessment for highway network construction in ecologically sensitive areas in western China and to enrich and consummate the theoretical method system in this field. Although this paper comprehensively assesses the feasibility of highway construction from two dimensions including construction necessity and ecological friendliness, the index system can be further enriched and deepened due to some objective factors such as the difficulty in obtaining some data. To some extent, highway construction will affect regional ecology, economy and other aspects, and damage the interests of some stakeholders. As a result, the results of assessment should be combined to the border with urban development, restriction requirements of construction land, and need to coordinate with the relevant administrative department for the maximization of the regional social, economical and ecological benefits. Due to the limited space and research priorities, these problems will further deepen in the follow-up study.

\section{References}

1. Shan, j.k., Wu, Y.Q. (2019) International experience and reference of eco-city construction. Study \& Exploration., 41: 121-125.

2. Qiu, T.X. (2019) Theoretical analysis of "traffic power" strategy in the new era. Journal of Beijing Jiaotong University (Social Sciences Edition)., 18: 58-62, 92.

3. Chen, W.W., Ou, G.L. (2019) Theoretical understanding of ecological traffic and evaluation of regional ecological traffic: a case study of Beijing. Ecological Economy., 35: 94-99.

4. Ficek, R. E. (2016) Imperial routes, national networks and regional projects in the Pan-American Highway, 1884-1977. Journal of Transport history., 37: 129-154.

5. Kalantari, Z., Folkeson, L. (2013) Road Drainage in Sweden: Current Practice and Suggestions for Adaptation to Climate Change. Journal of Infrastructure System.,19: 147-156.

6. Hyndman, P., Shoebotham, A., Hespe, 1. (2013) Design and construction of the Inner West Busway, Sydney, Australia. Proceedings of the Institution of Civil Engineers-civil Engineering., 166: 15-21.

7. Qin, X.C., Shen, Y., Meng, Q., et al. (2014) Highway Construction and Ecological Environment Protection: Corn Relationship and Key Principle. In: CEBM 2013. Hong Kong. pp. 287-292.
8. Yu, T., Bao, A.M., Liu, T., et al. (2019) Effects of different grades of roads on land use and landscape pattern in Manas river basin. Journal of Natural Resources., 34: 2427-2439.

9. Lin, Y.M., Ge, Y.G., Wang, D.J., et al. (2016) Influence of county and township highway construction in mountainous areas on landscape pattern along the route: a case study of Jiangjiagou watershed in Dongchuan district, Kunming city. Resources and Environment in the Yangtze Basin., 25: 1566-1575.

10. Guan, L., Jiang, S., Tao, S.C., et al. (2019) Study on the index system of regional ecological evaluation for the selection of route in highway feasibility stage: a case study of middle route expressway in Hainan province. Highway Engineering., 44: 57-62, 86.

11. Zhang, C., Wang, Z.F., Wang, Y.J., et al. (2019) TOPSIS and hotspot analysis based on the assessment of geological and ecological environment carrying capacity along Duwen highway. Journal of Glaciology and Geocryology., 41: 1-12.

12. Wang, H.J., Qing, C.Q., Deng, J. L., et al. (2019) Study on greening technology of existing hard slope of expressway. Highway., 64: 256-259.

13. Ye, J.J., Wang, B., Li, H., et al. (2019) Experimental study on ecological protection of embankment slope in nk-sg4 section of Manda highway. Highway., 64: 246-251.

14. Li, J., Xue, Z.N., Yang, H.Z., et al. (2018) Research on ecological evaluation method of karst geological highway route selection based on RS and GIS. Highway., 63: 220-226.

15. Zhu, G.R., Zhao, K., Liu, J., et al. (2019) Study on ecological conflict and coordination in highway network planning: a case study of Sanjiangyuan region on the Qinghai-Tibet plateau. Journal of Capital Normal University (Natural Science Edition)., 40: 1-8. 